\title{
Prevalence of Sarcosporidiosis in Carcasses of Cattle Slaughtered at the Eucalyptus Slaughterhouse-Algeria
}

\author{
Messaouda TAIBI ${ }^{1,2 *}$; Amel BENATALLAH ${ }^{1,3}$; Safia ZENIA ${ }^{1,2}$; Miriem AISSI ${ }^{1,2}$, Khaled HARHOURA ${ }^{1,2}$, \\ Amel MILLA $^{1,2}$, Amel GUERCHAOUI ${ }^{4}$; Imene KAABECHE ${ }^{4}$; Romeissa KHODJA ${ }^{4}$ \\ ${ }^{1}$ Higher National Veterinary School, Issad Abbes street, Oued Smar, Algiers 16000, Algeria \\ ${ }^{2}$ Research Laboratory -"Health and Animal Productions", Higher National Veterinary school of Algiers, Algeria \\ ${ }^{3}$ Research Laboratory of Food Hygiene and Quality Insurance System (HASAQ), Higher \\ National Veterinary School, of Algiers, Algeria \\ ${ }^{4}$ University of Sciences and Technology Houari Boumediene, El Alia, Bab Ezzouar, Algiers, 16111, Algeria \\ *corresponding author: m.taibi@ensv.dz
}

Bulletin UASVM Veterinary Medicine 77(2)/2020

Print ISSN 1843-5270; Electronic ISSN 1843-5378

doi:10.15835/buasvmcn-vm:2020.0008

\begin{abstract}
Sarcosporidiosis is a parasitic disease due to the development of cystogenic coccidia of the genus Sarcocystis with dixene evolution and muscular localization, which can cause losses in cattle and generate an intestinal infection in domestic carnivores (dog, cat) and humans. The objective of our study was to determine the prevalence of Sarcocystis spp on 149 bovine carcasses at the Eucalyptus slaughterhouse in Algiers by macroscopic and microscopic examination and to evaluate the influence of certain risk factors (age, sex, breed and origin). Samples of esophagus and diaphragms were taken from slaughtered cattle and analyzed by enzymatic (pepsin) digestion and histological technique. The macroscopic examination was negative during carcasses inspection while the microscopic examination showed a prevalence of $100 \%$ for enzymatic digestion by revealing bradyzoites in the form of bananas and $47.7 \%$ at the histology with the detection of thin-walled cysts of S. cruzi (98.6\%), of thickwalled cysts of S. hominis (15.5\%) which was the zoonotic species and of S. hirsuta (1.39\%). The risk factors studied significantly influenced the prevalence of Sarcocystis sp. This study revealed for the first time in the diaphragm a cyst of Sarcocystis hirsuta.
\end{abstract}

Keywords: bovines, enzymatic digestion, histology, risk factors, Sarcocystis

\section{Introduction}

Cattle were often exposed to multiple diseases, among them sarcosporidiosis, which affects both animal health and the quality of meat, as well as public health. Sarcosporidiosis is a parasitic disease caused by a protozoan of the genus Sarcocystis belonging to the phylum Apicomplexa, infesting humans and many animal species (Euzeby, 1997, 1998). These cystogenic coccidia have a dixene cycle, most of which involve herbivores or omnivores as intermediate hosts and carnivores and humans as final hosts (Cappelier et al., 2015).
The genus Sarcocystis infected generally the tissues of mammals, birds and reptiles and included more than 100 species that differ in pathogenicity, host specificity, structure and location of the Sarcocyst (Florin-Christensen and Schnittger, 2018).

Cattle were intermediate hosts for five species of Sarcocystis, namely S. cruzi, S. hirsuta, S. hominis, S. rommeli, and S. heydorni (Dubey et al., 2016), while canids, felines, primates, and humans were their final hosts respectively (Yang et al., 2018). 
In cattle, $S$. cruzi was the most pathogenic species that caused fever, weight loss, anorexia, abortion, neurological signs and death (Dubey et al., 2016). In contrast, $S$. hominis and $S$. hirsuta were less pathogenic and were associated with eosinophilic myositis lesions (Vangeel et al., 2013; Cappelier et al., 2014). Few reports on the pathogenicity of $S$. rommeli and $S$. heydorni in cattle and humans have been found.

In the majority of cases, cattle that have been infested with Sarcocystis spp. showed no clinical signs. If it has been described, the symptoms of bovine sarcosporidiosis were not specific, the parasite was only rarely sought, and the etiology of clinical sarcosporidiosis thus remained most often undetermined (Dubey and Lindsay, 2006). The importance of bovine sarcosporidiosis therefore has been seemed to be underestimated. In most parts of the world, the prevalence of Sarcocystis in cattle was extremely high (close to 100\%) however, the prevalence of eosinophilic myositis was very low (0.002\% to 5\%) (Vangeel et al., 2007).

In Algeria, several studies on bovine sarcosporidiosis have shown a high prevalence in different regions of our country but not all of them have been published. Nedjari (2002) and Harhoura et al. (2010) revealed prevalences of $63 \%$ and even reaching $100 \%$ on bovine carcasses at the slaughterhouses of Hussein dey and Rouiba respectively. Recently, the study which was carried out at the level of slaughterhouses in northern Algeria revealed a prevalence of $90 \%$ (TaibiMeksoud, 2016).

For this, our study aimed to determine the prevalence of sarcosporidiosis in the carcasses of 149 cattle slaughtered at the Eucalyptus slaughterhouse and to assess the influence of risk factors such as age, sex, origin and breed on this prevalence.

\section{Materials and methods Method of sampling}

Samples of meat were collected between November 2018 and March 2019 on 149 cattle slaughtered at the Eucalyptus slaughterhouse located in the province of Algiers, represented by 91 males (58 local and 33 imported) and 54 local females. The females were between 4 and 8 years old and the males were between 2 and 4 years old. At the slaughterhouse, a post-mortem examination was carried out on bovine carcasses for research macroscopic cysts. Esophagus samples of 8-12 $\mathrm{cm}$ length and $20 \mathrm{~g}$ of diaphragms were taken from each carcass and placed in identified freezer bags (sampling date, number, sex and the age of sampled cattle).The samples were transported to the parasitology and mycology laboratory of Higher National Veterinary School (ENSV) of Algiers

\section{Preparation of samples in the laboratory}

The samples were washed, the same day, with water to remove blood and food from the esophagus. They were cleaned of all fats and aponeuroses until obtaining clean muscles. The samples were divided into two parts: one part was stored in the freezer at $-20^{\circ} \mathrm{C}$ for enzymatic digestion and the other was fixed in formalin at $10 \%$ for histological study.

\section{Technical analysis}

Technique of enzymatic digestion

The principle of this technique was to reconstruct an artificial gastric juice called solution of digestion (1.3 g pepsin, $3.5 \mathrm{ml}$ of HCL at $25 \%$ and $2.5 \mathrm{~g} \mathrm{Na} \mathrm{Cl}$ in $500 \mathrm{ml}$ of distilled water). The latter combined the factors promoting the digestion of cysts and the release of bradyzoites, creating an optimum $\mathrm{pH}(\mathrm{pH}$ 1-3) which allowed the activation of pepsin (proteolytic enzyme) and the denaturation of proteins. For the peptic digestion of muscle samples (diaphragms and esophagus), we used the modified method of Seneviratna et al. (1975) which was cited by Latif et al. (1999). The samples were minced with a robot which was washed after each use and then weighed with an electronic scale.

$10 \mathrm{~g}$ of diaphragm and $10 \mathrm{~g}$ of esophagus from each carcass were collected in a graduated plastic tube, in which $50 \mathrm{ml}$ of digestion solution were added, the whole was homogenized using a spatula and incubated at $37^{\circ} \mathrm{C}$ with constant stirring for 30 minutes. The digest was then filtered with a sieve on which two gauze layers were deposited, to remove muscle debris. The obtained filtrate was centrifuged at $3000 \mathrm{rpm}$ for 5 minutes, the pellet was taken up in PBS (pH 7.2); the same operation was carried out twice, in order to stop digestion. A few drops of the pellet were aspirated and deposited on a slide for the preparation of smears and then were dried in the oven at $37^{\circ} \mathrm{C}$.

The dried smears were stained using the technique of May Grunwald Giemsa (Bussieras and Chermette, 1991) and were then observed 
under an optical microscope (Leica DMLS ®) at magnification $(\mathrm{x} 400, \mathrm{x} 1000)$. Sample was considered positive when typical bradyzoites of Sarcocystis were observed (banana shape).

\section{Histological technique}

The histological technique allowed not only the diagnosis of Sarcocystis infection but it also allowed the identification of the species involved. The steps of this technique were carried out at laboratories of Anatomy-pathology and Histopathology as well as Cytology of C.H.U. Nefissa Hamoud (Parnet) and Salim Zemirli in Algiers.

The histological technique was applied to all samples (diaphragms and esophagus). The method used was that cited by Hould et al.(1999), one square centimeter $\left(1 \mathrm{~cm}^{2}\right)$ of each muscle sample was processed by an automat device for complete dehydration and paraffin inclusion. The microtome section was then used to obtain sections of the order of 3 to $5 \mu \mathrm{m}$ thickness, deposited on slide and stained with hematoxylin and eosin (H\&E). The slides were read with an optical microscope at the magnification (x100, x 400, x 1000). The positive slides revealed presence of Sarcocystis cysts in the muscle fiber having a wall with variable thickness according to the species concerned (Gr.1000).

\section{Statistical analysis}

All the data collected were recorded and processed in Microsoft Excel 2016. The statistical analysis was performed using IBM $®$ SPSS $₫$ statistics version 20 software, which was used to calculate descriptive statistics: prevalence of Sarcocystis according to risk factors (origin, breed, sex and age) with a confidence interval at 95\%.

The data analysis was subjected to chi-square tests and to the calculation of the odds ratio in order to study the risk factors on the prevalence of Sarcocystis. The significance level was set at $\mathrm{P}$ $<0.05$.

\section{Results and discussions}

During the inspection of carcasses at the slaughterhouse, no macroscopic cyst or lesions of eosinophilic myositis were found. In contrast, microscopic sarcosporidiosis lesions have been observed. Enzymatic analysis revealed the presence Bradyzoites of Sarcocystis sp banana-shaped on all of the muscles (esophagus and diaphragm) analyzed on 149 cattle, which represented an infestation rate of $100 \%$. The bradyzoites of Sarcocystis sp. and numerous metrocytes were observed un- der an optical microscope (Gr x 400 and 1000) (Figure 1).

The histology revealed presence of sarcosporidian cysts, ellipsoidal in shape elongated in the direction of the muscle fibers, in 71 cattle, with an average prevalence of $47.7 \%=48 \% \pm 5.93 \%$ (39.60 - 55.7) \%. According to Wouda et al., 2006, the identification of the species involved was carried out by studying the wall of the cysts using morphological criteria during the observation of histological sections under an optical microscope. The enumeration of Sarcocystis cysts has revealed two types of cysts, thick-walled and thin walled, located inside the muscle fibers. Thin-walled Sarcocystis were characteristic of S. cruzi (Figure 2), while thick-walled Sarcocystis were represented either by $S$. hominis which was the zoonotic species (Figure 3), or S. hirsuta (Figure 4).

For these last two species, the differentiation of the two types of cysts was made by observing the cytophaners composing the wall of the cysts which can be long in shape, cylindrical at the base and almost perpendicular to the surface of the wall (in shape of fingers), characteristic of $S$. hominis (zoonotic species) (Figure 3), or long in shape, constricted at the base, conical and inclined in the distal part $\left(45^{\circ}-90^{\circ}\right)$ for S. hirsuta (Figure 4).

of the 71 parasitized cattle, 70 were infested with thin-walled cysts (98.6\%) and 11 with thick-walled cysts $(15.5 \%)$, of which 10 cattle were double infested with thin and thick-walled cysts $(14 \%)$ at the same time and only one cattle $(1.39 \%)$ showed a double infestation with thickwalled cysts of S.hominis and S.hirsuta (Figure 5).

For the intensity of cysts in both muscles, a total of 287 cysts were counted with 268 thinwalled and 18 thick-walled. The prevalence of sarcosporidian cysts in the infested diaphragms and esophaguses showed that thin-walled cysts remain dominant regardless of the parasitized muscle, with a high prevalence of $91 \%(101 / 111)$ in the esophagus and $97 \%(167 / 176)$ in the diaphragm.

Conversely, the prevalence of thick-walled cysts was very low (9\%) (10/111) and 5\% (9/176) in each of the muscles respectively. Indeed, all cysts were observed in 52 diaphragms and 47 esophagi. On the other hand, the prevalence of S.hirsuta was very low $(0.57 \%)$ and refound only in the diaphragm so for the intensity of parasitism, the diaphragm was more infested than the esophagus (Figure 6) 


\section{Risk factors analysis}

\section{Sex factor}

$30.8 \%(28 / 91)$ of males were infested with the Sarcocystis spp cysts compared to $74.1 \%$ $(43 / 58)$ females. The difference between the prevalence of the infestation for both sexes was highly significant $(\mathrm{P}<0.0001)$, the females were more infested than males. In addition, an Odd ratio value of 6.45 was recorded, which means that infestation with Sarcocystis sp cysts was 6-fold more frequent in females than in males (Table 1). The infestation according to the type of cyst reveals that thin-walled cysts of $S$. cruzi were predominant, regardless to the sex of carcass.

\section{Age factor}

149 cattle inspected were divided into three age groups. The first group consists of cattle under 2 years old with infestation prevalence of $28.8 \%$
(15/52). The second group consists on cattle between 2 and 4 years old with an infestation prevalence of $39.4 \%(13 / 33)$ and the final group consists of cattle over 4 years old with an infestation prevalence of 67.2\% (43/64). A highly significant difference $(\mathrm{P}<0.0001)$ was recorded between the infestation prevalences of the three age groups.

The prevalence of parasitism was very high in cattle over 4 years old, the study also revealed that infestation with Sarcocystis sp. cysts was 4 times more frequent in this age group compared to other age groups (odds ratio $=4.48)($ Table 1$)$. Thin-walled cysts of $S$. cruzi were predominant regardless of the age of cattle.

\section{Breed factor}

The cattle examined were from different breeds, among the beef carcasses which revealed

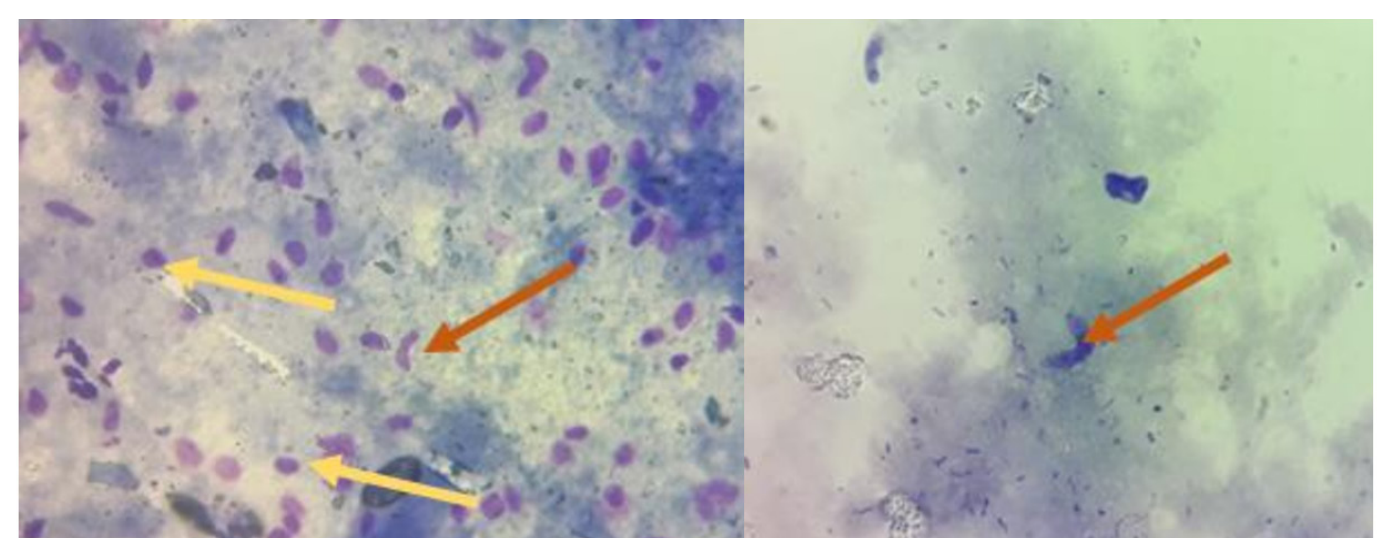

Figure 1. Bradyzoites (orange arrow) and metrocytes (yellow arrows) of sarcocystis sp. Stained with May Grunwald Giemsa, observed under a light microscope Gr x 400 (A); Gr x 1000 (B)

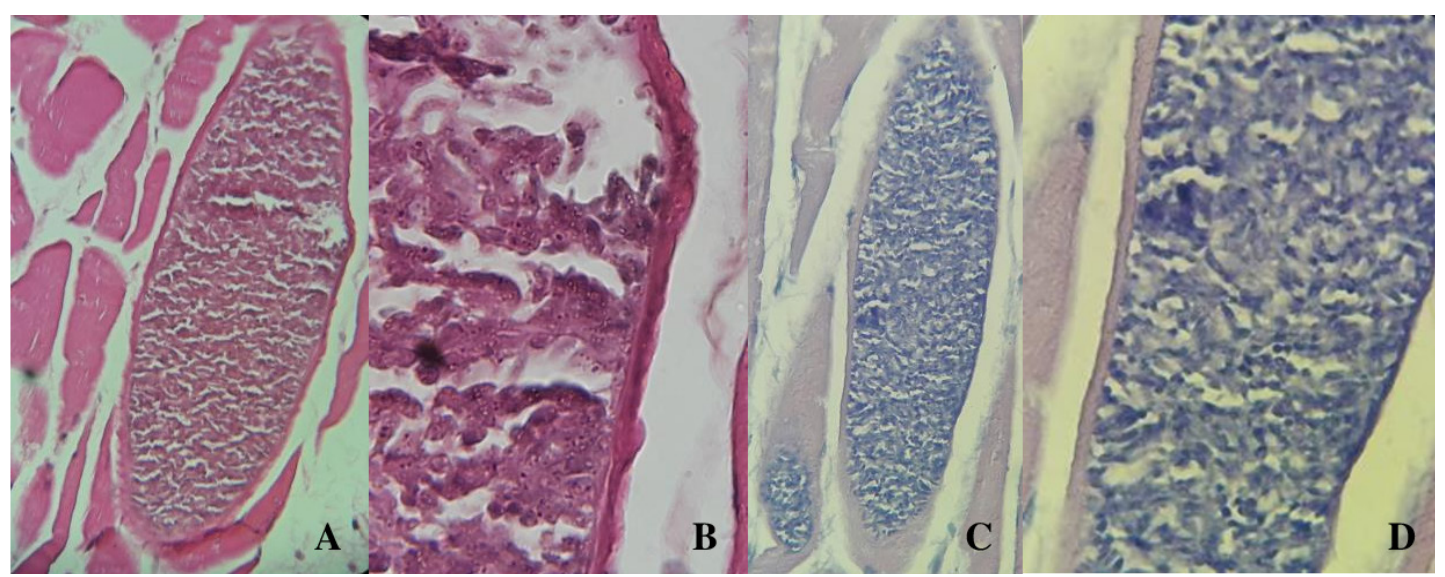

Figure 2. Thin-walled cyst of S. cruzi in longitudinal section observed under a light microscope (H \&E): Gr x 400 diaphragm (A); Gr x 1000 (B), Esophagus Gr x 400 (C); Gr x 1000 (D) 


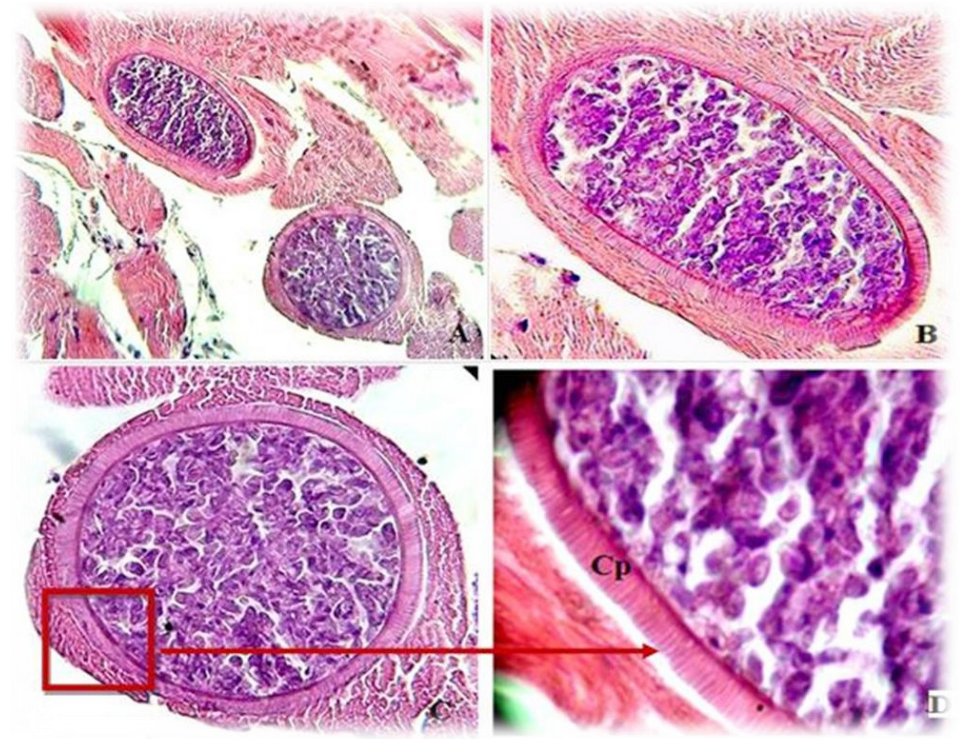

Figure 3. S. hominis cysts at the diaphragm (A); Longitudinal section (B); Cross section (C); (Cp): Cytophaners (D), observed under a light microscope (H\&E; Gr x 400; x 1000)

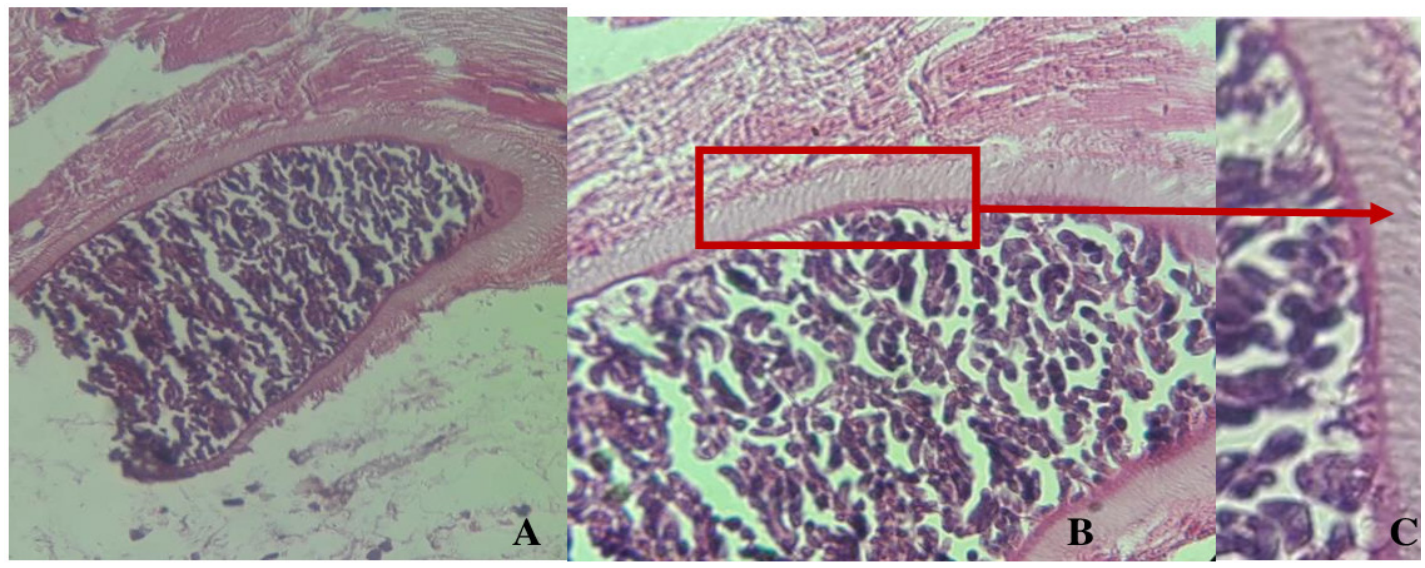

Figure 4. Thick-walled cyst of $S$. hirsute in longitudinal section at the level of the diaphragm, observed under a light microscope (H\&E): Gr x 400 (A); Gr x 1000 (red box) (B); observation of inclined and constricted cytophaners at the base (arrow) (Cp) Gr x 1000 (C)

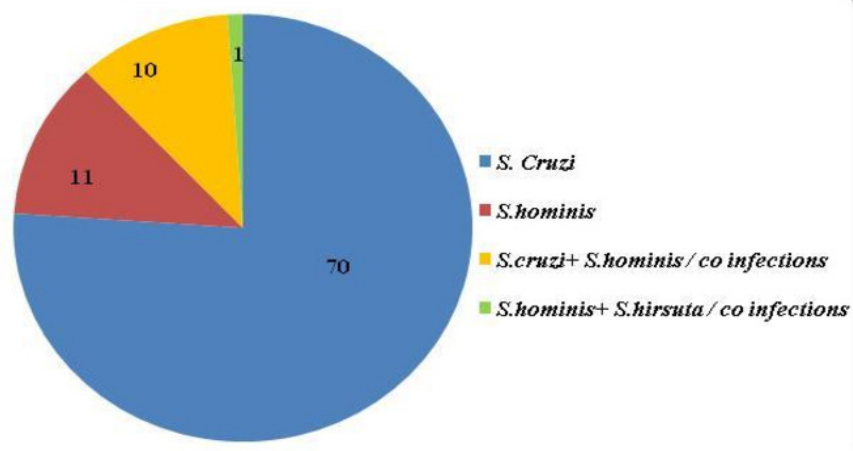

Figure 5. Cattles infested with Sarcocystis species 


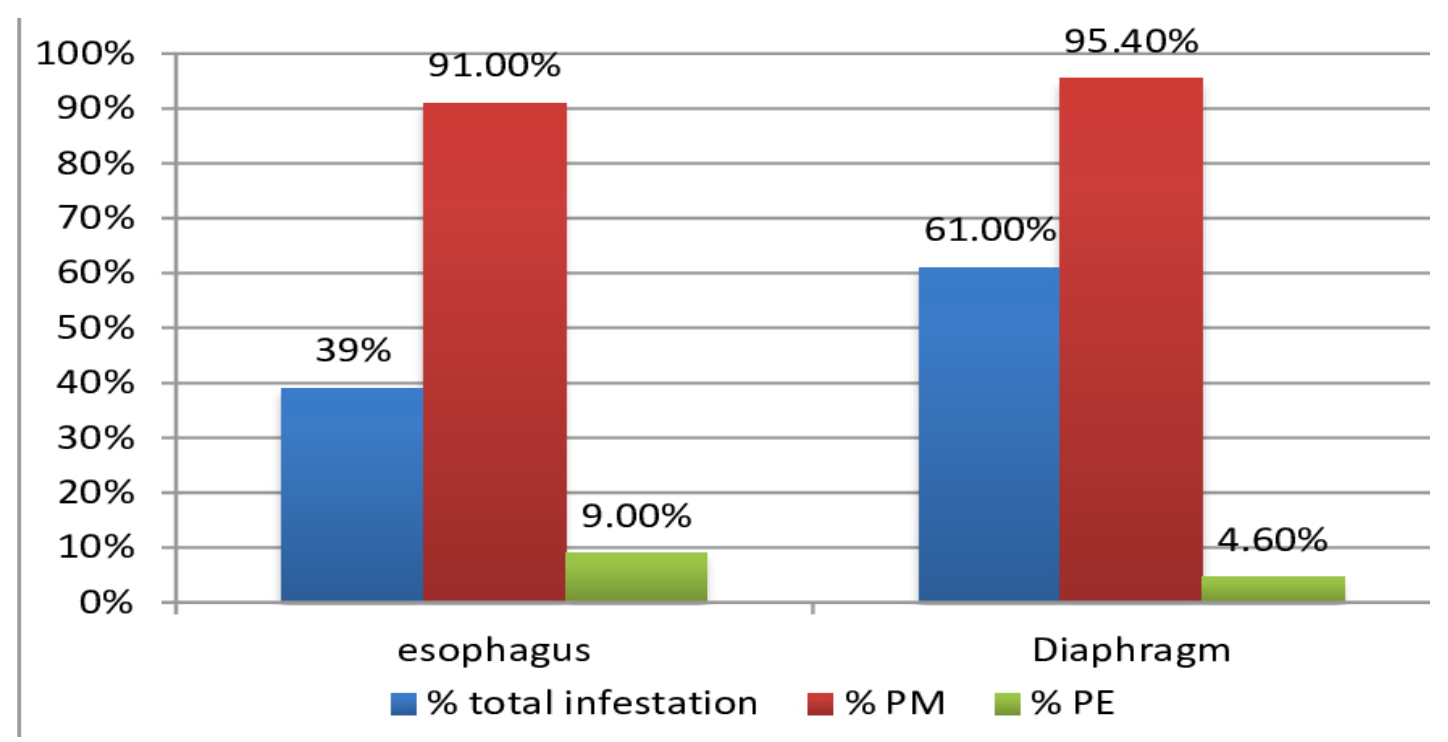

Figure 6. Prevalence of thin-walled (PM) and thick-walled (PE) sarcosporidia cysts in the diaphragm and esophagus

Table 1. Cattle prevalence by sex, age, breed and origin with their confidence interval at $95 \%$ and significance level $\mathrm{p}$

\begin{tabular}{|c|c|c|c|c|c|c|c|c|}
\hline $\begin{array}{l}\text { Risk } \\
\text { factors }\end{array}$ & Category & $\begin{array}{l}\text { Cattle } \\
\text { tested }\end{array}$ & $\begin{array}{c}\text { Posi- } \\
\text { tive } \\
\text { cattle }\end{array}$ & $\begin{array}{c}\text { Preva- } \\
\text { lence } \\
(\%)\end{array}$ & CI (\%) & p-value & $\begin{array}{c}\text { Odd } \\
\text { Ratio }\end{array}$ & CI (\%) \\
\hline \multirow[b]{2}{*}{ Sex } & Male & 91 & 29 & 31.9 & [22.29-41.44] & \multirow[b]{2}{*}{$\mathrm{P}<0.0001$} & 0.163 & [0.078-0.340] \\
\hline & Female & 58 & 43 & 74.1 & [62.87-85.41] & & 6.13 & $\begin{array}{l}{[2.939-} \\
12.778]\end{array}$ \\
\hline \multirow{3}{*}{ Age } & $<2$ years & 52 & 15 & 28.8 & [16.53-41.16] & \multirow{3}{*}{$\mathrm{P}<0.0001$} & 0.284 & [0.138-0.586] \\
\hline & $<4$ years & 33 & 13 & 39.4 & {$[22.72-56.07]$} & & 0.628 & [0.286-1.380] \\
\hline & $>4$ years & 64 & 44 & 68.8 & [57.39-80.11] & & 4.479 & [2.234-8.980] \\
\hline \multirow[b]{3}{*}{ Breed } & PN crossroads & 57 & 24 & 42.1 & [29.29-54.92] & \multirow[b]{3}{*}{$\mathrm{P}<0.003$} & 0.667 & $\begin{array}{c}{[0.342} \\
-1.298] \\
\end{array}$ \\
\hline & PR cross & 63 & 40 & 63.5 & [51.60-75.38] & & 2.935 & $\begin{array}{c}1.496- \\
5.758] \\
\end{array}$ \\
\hline & $\begin{array}{l}\text { Other } \\
\text { (Charolais + } \\
\text { Limousine + } \\
\text { Brown Swiss) }\end{array}$ & 29 & 8 & 27.6 & {$[12.73-47.24]$} & & 0.381 & $\begin{array}{c}{[0.161-} \\
0.900]\end{array}$ \\
\hline \multirow{4}{*}{$\begin{array}{l}\text { Origin } \\
\text { (Dis- } \\
\text { trict) }\end{array}$} & Center & 73 & 46 & 63.0 & [51.94-74.09] & \multirow{4}{*}{$\mathrm{P}<0.002$} & 3.276 & [1.675-6.410] \\
\hline & West & 34 & 12 & 35.3 & [19.23-51.36] & & 0.500 & [0.226-1.105] \\
\hline & East & 9 & 5 & 55,6 & [21.20-86.30] & & 1.362 & [0.351-5.285] \\
\hline & Importation & 33 & 9 & 27.3 & {$[13.30-45.52]$} & & 0.315 & {$[0.135-0.737]$} \\
\hline
\end{tabular}


positive, $63.5 \%(40 / 63)$ were of cross-breeds PR, against 40.4\% (23/57) cross-breeds PN and only $27.6 \%(8 / 29)$ for other breeds (Charolais, Limousin and Swis Brown). The difference between prevalence's infestation according to the breed of cattle has been highly significant $(P<0.002)$, infestation was very important in crossbred PR cattle. Analysis indicated that the presence of Sarcocystis sp. was 3 times more frequent in the cross breed PR than in the other infested breed (Odd Ratio $=3.086)($ Table 1$)$.

\section{Regarding the origin (provenance)}

$87.3 \%(62 / 71)$ of infested cattle were of local origin of which $63 \%(46 / 73)$ come from the provinces of central Algeria, 55.6\% (5/9) from the east and $32.4 \%(11 / 34)$ from the west against $27.3 \%$ of imported origin (France, Spain and Portugal). The prevalence of carcass infestation with Sarcocystis sp cysts by region has been highly different ( $\mathrm{P}<0.001)$. In addition, the analysis revealed that carcasses from central region provenance were three times more infested with Sarcocystis sp cysts (Odd Ratio: 3.476) (Table 1).

Comparison of prevalences between import and local cattle showed that 19 out of 60 local male cattle were parasitized (31.7\%) compared to 9 out of 31 imported male cattle that were infested (29\%).

In our study, no macroscopic cysts specific for sarcocystosis were detected on the 149 carcass inspected, our results were in agreement with the works of Nedjari (2002), Harhoura et al. (2010) and Taib et al. ( 2016) in the slaughterhouses of Algiers, Rouïba and El Harrach in Algeria, on the other hand, Taibi-Meksoud (2016) was reported a prevalence of $0.2 \%$. In Iraq, the same prevalence $(0.2 \%)$ was noted by Latif et al. (1999) and in Iran, Mirzael and Rezaei (2016) were detected a prevalence of $8.2 \%$ of macroscopic Sarcocystis cysts. Shekarforoush et al. (2013), were reported the first occurrence of macroscopic Sarcocystis of $S$. hirsuta distributed in different striated muscles (intercostal and diaphragm) in cow of 2 years old slaughtered at the Shiraz slaughterhouse in southern Iran. The greatest prevalences were recorded in China by Shi and Zhao (1987) detected macroscopic cysts of Sarcocystis sp to 64,78\%, this supposes that cat species of $S$. hirsuta was more predominant.

In our samples, the absence of macroscopic cysts was probably related to the low prevalence of the feline specie (Latif et al., 1999, Nourollahi Fard et al., 2009). This hypothesis could be explained by the fact that cats were rarely in contact with cattle on pastures and farms and also by the fact that cats bury their faeces after defecation, which makes the pasture soil less contaminated with feline oocysts. Generally, no macrosopic lesions were observed in cattle and diagnosis depends on microscopic examination of muscle samples taken from target tissues such as the heart, tongue, esophagus and diaphragm (Dubey et al., 2016).

Experimental infestations with macroscopic cysts isolated from bovine skeletal muscle on two cats, two dogs and a volunteer human showed that only cats excreted oocysts, from which the authors concluded that the macroscopic cysts were those of S.hirsuta (Bottner et al., 1987).

The same experiment was reproduced by the team of Aissi et al. (2013), who found oocysts $S$. cruzi after infestation of cats, dogs and primates (maggot monkeys) by portions of muscle infested with microscopic cysts.

For the detection of Sarcocystis by the enzymatic digestion technique, according to Euzeby, 1987 and Fassi-Fehri et al., 1978, the infestation of muscles by Sarcocystis was similar.

Also, we have in our study, mixed two muscles (esophagus and diaphragms) for enzymatic digestion technique. Microscopic examination of our samples revealed a prevalence of $100 \%$. The majority of studies on bovine sarcosporidiosis had related high prevalences and appeared to be widespread in all countries and slaughterhouse screenings reported that $100 \%$ of animals have been affected (Zenner et al., 2005) as the works of Nourollahi Fard et al., 2009 in Iran and Italy, where prevalences of $96 \%$ (Bucca et al., 2011), greater than $80 \%$ (Domenis et al., 2011) and 91\% (Chiesa et al., 2013 ) were detected.

In Algeria, similar results have been reported by Harhoura et al., 2010 (100\%) and Taib et al., 2016 (95\%). In contrast, in Egypt, Nahed et al., (2014) revealed the presence of bradyzoites in $60 \%$ of cattle taken from different slaughterhouses in Cairo and Giza.

In our study, the heavy infestation of cattle with Sarcocystis could be attributed to extensive pollution of pastures and farms by sporocysts excreted in the faeces of definitive hosts. Sarcocystis sp. was remarkably high because on the one hand, the dog, the cat and the man could 
be behind this strong infestation if they emitted significant quantity of sporocysts in faeces (Fayer, 1974; Fassi- Fehri et al., 1978).

Furthermore, a study in the north of Western Australia showed that $31.2 \%$ of cattle were infested by Sarcocystis spp. This low prevalence can be explained by an unfavorable climate for the survival of cysts in fact the northern part of Western Australia was characterized by a very arid climate; the survival of cysts was not favored in this environment (Savini et al., 1994).

Histological examination of muscles showed that $47 \%$ of cattle were infested with cysts of Sarcocystis. This was in agreement with those which were obtained by Savini et al. (1992) in Australia, Algeria (Nedjari, 2002), Nigeria (Obijiaku et al., 2013), Malaysia (Latif et al., 2013), Italy (Meistro et al., 2015) and China (Yang and al., 2018), on the other hand, higher prevalences in other countries (70-98\%) were published as in Ethiopia by Woldemeskel and Gebreab, 1996 and Mekibib et al.(2019) , in France ( Mary, 2005), in Morocco (Fassi-Fehri et al., 1978), in Iran (Nourani et al., 2010), in Hungary (Hornok et al. 2015) and in Lithuania (Januskevicius et al., 2019).

Also, the histology showed that $97 \%$ of parasitized cattle were infested with thin-walled cysts (S.cruzi), while only $16 \%$ have thick-walled cysts (S.hominis and S.hirsuta). Our results were similar to those obtained by Taibi-Meksoud (2016) who has noted a prevalence of $98 \%$ of infested cattle with thin-walled cysts and $9 \%$ with thickwalled cysts, and Benamghar (2019) with 92.63\% thin-walled cysts, while only $17.89 \%$ thick-walled cysts. Nedjari (2002), noted the prevalence of S.cruzi cysts in $60.22 \%, 36.46 \%$ of S.hirsuta cysts and $3.31 \%$ of S.hominis cysts in esophagus and Harhoura et al., (2010) found an infestation rate of. $S$ cruzi cysts of $60.8 \%$ in the esophagus and $79.8 \%$ in the diaphragm and a thick-walled cysts infestation rate of $7.5 \%$ in the esophagus and $23.5 \%$ in the diaphragm. On the other hand, in France some authors noted a predominance of thick-walled cysts of $S$. hominis with prevalence varying from $66 \%$ to $88.6 \%$ (Bertin et al., 2014; Lemieux, 2014). In Italy, prevalence vary from $80 \%$ for S.cruzi, $68 \%$ for S. hominis and $4 \%$ for S. hirsuta (Meistro, 2015). In Japan, the existence of S. hirsuta infection in cattle was first reported by Inoue et al. in 1990. In our study, thick-walled cysts were found only in the diaphragms with a very lower prevalence. Our results were consistent with the work of Ruas et al. (2001) which also showed that $S$. hirsuta cysts were found only in the diaphragm with a lower prevalence (1.4\%).

In Germany, S. cruzi (52\%), S. sinensis (37\%), S. hirsuta (6.6\%) and S. hominis (6.2\%) were found in samples from cattle studied (More et al., 2014). The study carried out in Hungary showed that S.cruzi (64\%), S. hominis (19\%) and S. sinensis $(17 \%)$ were the most widespread species (Hornok et al., 2015). In our study, the species $S$. sinensis was not found.

Given the predominance of thin-walled cysts, it can be concluded that cattle were therefore contaminated by ingestion of sporulated oocysts rejected by domestic carnivores, especially dogs and secondarily by humans through the transmission of the zoonotic species $S$. hominis (thick-walled cyst). Excretion of oocysts and sporocysts by final hosts was the key factor in the propagation of infection (Dubey and Lindsay, 2006).

\section{For risk factors}

Based on sex, in general, we have noted a significant difference between the degree of infestation of males and females. Noted that females were more infested than males. The same results were found by Mohanty et al. (1995) and Bertin (2013). Unlike, Najaflan et al. (2008), Nourollahi Fard et al., (2009) how noted no influence of sex on the prevalence of Sarcocystis.

Regarding age, the cattle older than 4 years were more infested (67\%). Our results were in agreement with those of Seneviratna et al. (1975), Savini et al. (1992), Parky et al. (1994), Guenegan (2009). All these studies have shown that age influenced the prevalence of microscopic cysts and that infestation increased with age. These results could be explained by the fact that older animals were in contact with oocysts and sporocysts that infested pastures for a longer time period and consequently more infested than younger animals. On the other hand, calves begin to become infested at about 3-4 months of age. Indeed, at this age, they increased their grass consumption and were therefore more in contact with sporocysts (More et al., 2009). In Algeria, no influence of age has been revealed by Nedjari (2002) and Taibi et al. (2016).

In our analysis, the prevalence of microscopic cysts of Sarcocystis sp. was influenced by the breed factor. In fact, red and black crossbred and 
Charolais cattle influenced the prevalence of Sarcocystis sp. Our results were similar to those of Nourollahi Fard et al. (2009). On the other hand, Harhoura et al., (2010) showed that there was no significant difference between breeds.

Concerning the origin of the animals, cattle from the region of center Algeria appeared to be more infected. In Algeria, prevalences ranging from $38 \%$ to $89 \%$ were found in the center region and with variable rates for the other zones: East (34.43\%), West (15.65\%) and South (1.91\%) (Lardjane et al., 2014 and Taibi-Meksoud, 2016). The influence of these regions on the prevalence of Sarcocystis sp. could be explained by the Mediterranean climate known for long, hot and dry summers with mild and wet winters. According to Seneviratna et al. (1975), transmission took place during the rainy season (July to October) during which conditions were favorable for the development of Sporocysts.

Other factors may influence the prevalence of infestation by Sarcocystis species, such as environmental and management factors such as the method of husbandry and grazing practice (Meshkov, 1975). Indeed, this author found that the weakest cases of infestations were observed in calves which were kept in closed farms, which revealed a low parasite load in calves grazing on grass in uncontaminated areas respecting good hygiene and therefore not exposed to risk factors such as contaminated pastures.

\section{Conclusion}

This study confirmed that cattle slaughtered at Eucalyptus slaughterhouses (Algiers) were not free from sarcosporidiosis. The results showed a strong infestation of $100 \%$ thanks to the enzymatic digestion method. Histological examination, on the other hand, allowed us to highlight two types of Sarcocystis cysts, those with thin walls of S.cruzi which was the predominant species in bovine carcasses and thick walls of $S$. hominis and $S$ hirsute, which were less numerous. Our study also has demonstrated the important role of the dog in the circulation of Sarcocystis and in a weaker way of the man and the cat. The detection of the zoonotic species of $S$. hominis was in favor of a human contribution in the contamination of cattle by Sarcocystis; moreover, this would also reflect certain dietary habits such as the consumption of raw or undercooked meat with harmful consequences for public health. To consolidate these results, a study on the molecular identification of isolated species may be necessary.

Finally, to conclude, the health and economic aspects of bovine sarcosporidiosis were difficult to estimate because it was often an asymptomatic parasitosis. The economic losses associated with infection were very poorly documented. Due to the high prevalence of infection, they could be significant and result in stunted growth, impaired reproduction and reduced milk production. Therefore, in order to reduce the prevalence of this parasite and thus its zoonotic and economic impact, efforts should be made to break the life cycle through awareness rising.

Acknowledgments. This research did not receive any specific grant from funding agencies in the public, commercial, or not-for-profit sectors.

\section{References}

1. Aissi M, Harhoura KH, Khouni F (2013). Prevalence and study of the bovine Sarcocystis species in the slaughterhouses of Rouiba (Algiers). Journal of Veterinary Science \& Technology 04:127-128. Doi:10.4172/21577579.1000127

2. Benamghar F (2019). Comparative study of bovine sarcosporidiosis prevalence at 3 Slaughterhouses in Northen Algeria: El Harrach, Bordj Bou Arreridj and Tiaret. Higher National Veterinary School of AlgiersAlgeria, 59 p. «Unpublished results ».

3. Bertin M (2013). Eosinophilic myositis and sarcosporidiosis cattle: involvement of different species of Sarcocystis spp. PhD thesis veterinarian. Nantes Faculty of Medicine, Oniris: National Veterinary School, food and nutrition Atlantic Nantes p: 136. «Unpublished results ».

4. Bertin M, Lemieux D, Rossero A, Albaric O, Oudot N, Willemse C, Chiesa F, Magra C, Capplier JM (1014). Sarcocystis hominis is frequently associated with bovine eosinophilic myositis. Renc. Rech. Ruminants 21: 321324.

5. Bottner A, Charleston WA, Pomroy WE, Rommel M (1987). The prevalence and identity of Sarcocystis in beef cattle in New Zealand. Vet. Parasitol 24: 157-168. Doi: 10.1016/0304- 4017 (87) 90036-7.

6. Boussebata K, Chaouia D, Souat N (2014). Contribution to the study of bovine sarcosporidiosis in the region of eastern Algeria. Memory. Master: parasites option: Biology, Ecology and Environment. Algiers USTHB p: 36. «Unpublished results ».

7. Bucca M, Brianti E, Giuffrida A, Ziino G, Cicciari S, Panebianco A (2011). Prevalence and Distribution of Sarcocystis spp. cysts in several muscles of cattle slaughtered in Sicily, Southern Italy. Food Control 22:1058. Doi:10.1016/j.foodcont.2010.05.015. 15. 
8. Bussieras J, Chermette R (1991). Abrégé de parasitologie vétérinaire. Edité par le service de parasitologie Ecole Nationale Vétérinaire : Alfort Cedex (France). Oxford University Press .73 pp.

9. Cappelier JM, Lemieux D, Bertin M (2015). Parasites in cattle. Sarcosporidiosis and eosinophilic myositis: occult causes total seizure. The Veterinary Point $p p n^{\circ} 356,46-$ 52.

10. cattle in Japan. Japanese Journal of Parasitology Vol.39 $\mathrm{N}^{\circ} .4$ pp.403-405.

11. Chiesa F, Muratoire E, Dalmasso A, Civera T (2013). A new molecular approach to assess the occurrence of Sarcocystis spp. in cattle and products there of preliminary data. Ital J Food Safety 2:e41. Doi:10.4081/ijfs.2013.e41.

12. Domeni L, Peletto S, Sacchi L, Clementi E, Genchi M, Felisari L, Felisari C, MO, Modesto P, Zuccon F, Campanilla C, Maurella C, Guidetto C, Acutis P (2011). Detection of a morphogenetically novel Sarcocystis hominis-like in the context of a prevalence study in semi-intensively bred cattle in Italy. Parasitol Res 109:1677-87. Doi:10.1007/ s00436-011-2441-1.

13. Dubey JP, Calero-Bernal R, Rosenthal BM, Speer, CA, Fayer R (2015). Sarcocystosis of Animals and Humans. (2nd ed.). CRC Press, Boca Raton. (pp.510) (Chapter 7). Doi: 10.1201/b19184.

14. Dubey JP, Calero-Bernal R, Rosenthal, BM, Speer CA, Fayer R (2016). Sarcocystosis of Animals and Humans. CRC Press, Taylor \& Francis Group. ( pp. 481). Doi :10.1201/ b19184.

15. Dubey JP, Lindsay DS (2006). Neosporosis, toxoplasmosis, and sarcocystosis in ruminants. Vet Clin Food Anim 22:645-71. Doi: 10.1016/j.cvfa.2006.08.001.

16. Euzeby J (1987). Protozoologie medical compare. Volume II: Myxozoa-Microspora-Ascetospora-Apicomplex, I: Coccidioses (sensu lato). Section 3 : Coccidioses histocystogènes: tissu mésenchymateux et parenchymes. Collection Fondation Marcel Mérieux. Lyon p. 475.

17. Euzeby J (1998). Les parasites des viandes : Epidémiologie, physiopathologie, incidences zoonosiques. Tec \& Doc p.402.

18. Fassi-Fehri N, Cabaret J, Amaqdouf A, Dardar R (1978). The sarcosporidiosis ruminants in Morocco. Epidemiological study of two histological techniques. Ann Rech Vet 9: 409417.

19. Fayer R (2004). Sarcocystis spp. in human infections Clinical Microbiology Reviews 17: 894-902. Doi: 10.1128/ CMR.17.4.894-902.2004

20. Florin-Christensen M, Schnittger L (2018). Parasitic Protozoa of Farm Animals and Pets. Cham: Edition Springer International Publishing. Springer (pp.438). Doi: 10.1007/978-3-319-70132-5.

21. Guenegan C (2009). Risk factors for seizure in slaughterhouses for sarcosporidiosis in cattle: study in The Loire region. Doctoral thesis: Farm Animal Health and Public Health.Nantes, National Veterinary School of Nantes p.124. «Unpublished results».

22. Harhoura KH, Khouni F, Aissi M (2010). Prévalence de sarcocystis sp. dans les carcasses bovines au niveau des abattoirs de rouiba (Alger). In: Medimond, S.R, Monduzzi, L. (eds.) XII International Congress of Parasitology (I.C.O.P.A.), Melbourne (Australia), August pp.15-20.

23. Hornok S, Mester A, Takacs N, Baska F, Majoros G, Fok E, Biksi I, Nemet Z, Hornyak A, Janosi S, Farkas R (2015). Sarcocystis-infection of cattle in Hungary. Parasites \& Vectors 8:69. Doi: 10.1186/s13071-015-0685-9.

24. Hould R (1999). Techniques d'histopathologie et de cytopathologie (Montréal : CCDMD), p. 150.

25. Inoue I, Yamada C, Yamada M, Kondo T (1990). Sarcocystis hirsuta (Protozoa, Apicomplexa) in

26. Januskevicius V, Januskeviciene G, Prakas P, Butkauskas D, Petkevicius S (2019). Prevalence and intensity of Sarcocystis spp. infection in animals slaughtered for food in Lithuania. Veterinari Medicina, 64 (04): 149-157. Doi: 10.17221/151/2017-VETMED.

27. Lardjane N, Menasri F, Tighouart F (2014). Contribution to the study of bovine sarcosporidiosis in the Region of Algeria's Centre. Master memory option: Parasites: Biology, Ecology and Environment. University of Technological Sciences Houari Boumediene (U.S.T.H.B.), Algiers (pp.30). Unpublished Results ».

28. Latif BM, Al-Delemi JK, Mohammed BS, Al-Bayati SM, AlAmiry AM (1999). Prevalence of Sarcocystis spp. in meatproducing animals in Iraq. Vet Parasito 184: 85-90. Doi: 10.1016/s0304- 4017(99)00046-1.

29. Latif BM, Vellayan S, Heo CC, Kannan Kutty M, Omar E, Abdullah S, Tappe D (2013). High prevalence of muscular sarcocystosis in cattle and water buffaloes from Selangor, Malaysia. Trop Biomed 30 (4): 699-705.

30. Lemieux D (2014). Myositis and eosinophilic Sarcosporidiosis Bovine Study Aimed at the Blonde d'Aquitaine. State Doctoral thesis: Biology, Pathology and Science of the food. Nantes National Veterinary School, food and nutrition p.140. «Unpublished results ».

31. Mary N (2005). Beef sarcosporidiosis: Role in lesions myositis eosinophilic and species involved. Veterinary doctoral thesis. ENV Nantes (pp.83). « Unpublished results ».

32. Meistro S, Peletto S, Pezzolato M, Varello K, Botta M, Richelmi G, Biglia C, Baioni E, Modesto P, Acutis P, Bozetta E (2015). Sarcocystis spp. prevalence in bovine minced meat: a Histological and molecular study. Italian Journal of Food Safety 4:46.26: 85-87.

33. Mekibib B, Abdisa D, Denberga Y, Abebe R (2019). Muscular Sarcocystis infection in ruminants Slaughtered at Municipality abattoir and selected Hotels in Hawassa city, southern Ethiopia: Prevalence and associated risk factors. Veterinary Parasitology: Regional Studies and Reports 18: 100333. Doi: 10.1016/j.vprsr.2019.100333.

34. Meshkov S (1975). Sarcosporidia and Sarcosporidiosis in agricultural animals. Sarcosporidiosis in Cattle. Veterinarno-Meditsinski.Nauki 12 (5): 55-61

35. Mirzaei M, Rezaei H (2016). The role of sheep in the epidemiology of Sarcocystis spp. in Tabriz Area northwest of Iran. Journal of Parasitic Diseases 40: 285-288. Doi: 10.1007/s12639-014-0495-6. 
36. Mohanti B, Misra S, Panda D, Panda M (1995). Prevalence of Sarcocystis infection in Ruminants in Orissa. Indian. Veterinary Journal 72:1026-1030.

37. More G, Bacigalupe D, Basso W, Rambeaud M, Beltrame F, Ramirez B, Venturini MC, Venturini L (2009). Frequency of horizontal and vertical transmission for Sarcocystis cruzi and Neospora caninum in dairy cattle. Veterinary Parasitology 160: 51-54. Doi:10.1016/j.vetpar.2008. 10. 081.

38. More G, Pantchev A, Skubala J, Langenmayer MC, Masimov P, Conraths FJ, Venturi MC, Schares G (2014). Sarcocystis sinensis is the most prevalent thick-walled Sarcocystis species in beef on sale for consumers in Germany. Parasitology Research 113: 2223-2230.Doi: 10.1007/ s00436-014-3877.

39. Nahed HG, Wafaa WMR, Nader MS (2014). Occurrence of Zoonotic Sarcosporidiosis in Slaughtered Cattle and Buffaloes in Different Abattoirs in Egypt. Global Veterinaria 13: 809-813.

40. Najafiyan HR, Mohebali M, Keshavarz H (2008). Study on frequency of Sarcocystis spp. by macroscopic and microscopic methods in slaughtered cattle in Shahriar district and their public health importance. Pajouhesh-vaSazandegi 77: 15-19.

41. Nedjari MT (2002). Animal sarcosporidiosis. Results of a survey in the region of Algiers. Science and Technology pp. 71-73.

42. Nourani H, Matin S, Nouri A, Azizi HR (2010). Prevalence of thin-walled Sarcocystis cruzi and Thick-walled Sarcocystis hirsuta or Sarcocystis hominis from cattle in Iran. Trop Anim Health Prod 42: 1225-1227. Doi: 10.1007/s11250010-9552-z.

43. Nourollahi-Fard SR, Asghari M, Nouri F (2009). Survey of Sarcocystis infection in slaughtered cattle in Kerman, Iran. Tropical Animal Health and Production 41: 1633-1636. Doi: 10.1007/s11250-009- 9358-z.

44. Obijiaku IN, Ajogi I, Umoh JU, Lawal IL, Atu BO (2013). Sarcocystis infection in Slaughtered cattle in Zango abattoir, Zaria-Nigeria. Vet. World. 6: 346-349. . Doi: 10.5455/ Vet World. 2013.346-349.

45. Park YJ, Kim JS, Joeung DS, Sin MK, Kim KS, Kim TJ (1994). A survey of Sarcocystis Infections in the slaughtered cattle and identification of Sarcocystis cruzi. Korean J Vet Publ Hlth 18:251-259.

46. Ruas JL, Cunha CW, Silva SS (2001). Prevalence of Sarcocystis spp. (Lankester, 1882) in Clinically healthy cattle, the southern region of Rio Grande do Sul, Brasil. Journal of Agrociência 7: 227-230.

47. Savini G, Dunsmore JD, Robertson ID, Seneviratna P (1992). The epidemiology of Sarcocystis spp. in cattle of
Western Australia. Epidemiol Infect 108: 107-113. Doi: 10.1017/s0950268800049554.

48. Savini G, Robertson ID, Dunsmore JD (1994). Risk factors associated with the occurrence of Sarcocystosis in Western Australia: results of a postal survey. Preventive Veterinary Medicine 19: 137-144. Doi: 10.1016/01675877(94) 90046-9

49. Seneviratna P, Edward AG, Degiusti DL (1975). Frequency of Sarcocystis spp in Detroit, Metropolitan area, Michigan. Am J Vet Res 36 (3): 337-339.

50. Shekarforoush SS, Razavi SM, Abbasvali M (2013). First detection of Sarcocystis hirsuta from Cattle in Iran Iranian Journal of Veterinary Research, Shiraz University, 2013, Vol.14, No. 2, pp. 155-157. Doi:10.22099/ijvr.2013.1591.

51. Shi, L., Zhao, H. (1987). Evaluation of an enzyme immunoassay for the detection of a antibodies against Sarcocystis spp.in naturally infected cattle in china. Veterinary Parasitology 24:185-194. Doi: 10. 1016 / 0304-4017 (87)90039-2.

52. Taib M., Harhoura, KH., Aissi, M., Chaouadi, M., Djouhri, Y. (2016). Study of the Bovine Sarcosporidiosis in the Slaughterhouses of the North of Algeria: Case of the Slaughterhouses of El Harrach (Algiers). Cell Dev Biol 5: 167. Doi: 10.4172/2168-9296.1000167.

53. Taibi-Meksoud, M. (2016). Etude sur la sarcosporidiose bovine au niveau des abattoirs du Nord de L'Algérie. Ecole Nationale Supérieure Vétérinaire. Alger, p.173. "Unpublished results"

54. Vangeel L, Houf K, Geldhof P, De Preter K, Vercruysse J, Ducatelle R, Chiers K (2013). Different Sarcocystis spp. are present in bovine eosinophilic myositis. Vet Parasitol 197:543-8.

55. Vangeel, L., Houf, K., Chier, K., Vercruysse, J., D’Herde, K., Ducatelle, R. (2007). Molecular based Identification of Sarcocystis hominis in Belgian minced beef. J Food Protect 70:1523-6. Doi: 10.4315 /0362-028X-70.6.1523.

56. Woldemeskel, M., Gebreab, F. (1996). Prevalence of Sarcocystis in livestock of northwest Ethiopia. Zentralbl Veterinarmed 43: 55-58. Doi:10.1111/j.1439-0450.1996. tb00287.x.

57. Wouda, W., Snoep, J.J., Dubey, J.P. (2006). Eosinophilic myositis due to Sarcocystis hominis in a beef Cow," Journal of Comparative Pathology, vol. 135, no. 4, pp. 249-253. Doi:10.1016/j.jcpa. 2006.07.004.

58. Yang, Y., Dong, H., Su, R., Wang, Y., Wang, R., Jiang, Y., Tong, Z. (2018). High prevalence of Sarcocystis spp. infections in cattle (Bos taurus) from central China. Parasitology International 67: 800-804. Doi: 10.1016/j. parint.2018.08.006.

59. Zenner, L., Callait Cardinal, M.P., Chauve, C. (2005). La sarcosporidiose bovine. Bulletin des GTV 32: 27-32. 